\title{
Spatial variation in subtidal plant communities around the Socotra Archipelago and their biogeographic affinities within the Indian Ocean
}

\author{
Tom Schils* , Eric Coppejans \\ Phycology Research Group, Biology Department, Ghent University, Krijgslaan 281 (S8), 9000 Ghent, Belgium
}

\begin{abstract}
The subtidal plant communities of the Socotra Archipelago were studied by means of quadrat sampling. Ordination and statistical analyses revealed 6 distinct clusters corresponding to the geographic location and the physico-chemical factors. The north coast of Socotra Island supports algae commonly found in the Indian Ocean, with an intermediate species richness and alpha diversity for the archipelago. This entity includes 2 species-poor subentities: the seagrass beds and the coral-dominated communities. The transition zone is an overlapping area between Socotra's north and south coast where the greatest similarity in community structure with the upwelling flora of the south coast is found, owing to similar environmental conditions. This zone is subject to intense current patterns favouring a pronounced diversity of red algae. The south coast features the highest number of recorded species and a lower affinity with the (sub-)tropical Indian Ocean flora, and is marked by disjunctly distributed species. The plant communities of the outer islands comprise a mixture of the other entities due to the drastically changing seasonal environmental conditions in a limited coastal area. The intermediate character of this entity, i.e. ongoing competition amongst biota without reaching a climax in the vegetation succession, is reflected in the vegetation analyses and the biogeographic comparison.
\end{abstract}

KEY WORDS: Algae $\cdot$ Arabian Sea $\cdot$ Biogeography $\cdot$ Indian Ocean · Seagrasses $\cdot$ Seaweeds $\cdot$ Socotra

\section{INTRODUCTION}

The Socotra Archipelago (12.47 $\mathrm{N}, 53.87^{\circ} \mathrm{E}$; Yemen) is situated in the SW part of the Arabian Sea (see Fig. 1) and is affected by various gyres and eddies that result in upwelling during the SW monsoon in summer. The south coast of the main island is particularly influenced by the upwelling phenomenon, whereas the north coast is typified by warmer water with smaller temperature fluctuations. Biogeographic studies of Socotra's marine fauna (Kemp 1997, 1998b) show that many species are widespread throughout the IndoPacific and the Red Sea. In addition, the diverse habitats of the archipelago constitute an important refuge for closely related species from the Indian Ocean, Arabian Sea, Red Sea and Gulf of Aden (sympatry). Many species of the surrounding seas have their outermost distribution limits around Socotra, making it an impor- tant haven for larval stages and their dispersal throughout the Indian Ocean, the Red Sea and the Arabian Sea. Kemp (1998b) concluded that this southern Arabian region might be an extension of the upwelling region of Oman, characterized by a distinct species composition and a pronounced degree of endemism (Sheppard \& Salm 1988, Randall \& Hoover 1995).

Despite limited studies on Arabian Sea macroalgae, Børgesen (1934) commented on the peculiar flora of the area and its biogeographic affinities with distant regions. In the 1990's renewed interest in the marine biology of the region arose, including phycological studies. Ormond \& Banaimoon (1994) studied the algal assemblages in relation to physico-chemical characteristics along the upwelling coast of Hadramout (Yemen). Numerous taxonomic studies on the seaweeds of upwelling areas in Oman were initiated 
by Wynne (Wynne \& Banaimoon 1990, Wynne 1998, 1999a,b, 2001, Wynne \& Jupp 1998). The large number of new records and newly described species in these studies illustrate the lack of knowledge of the Arabian Sea flora.

Early phycological studies on the Socotra Archipelago are limited to Dickie (1888) and Holmes (1903), who reported 27 marine algae for Socotra Island and Abd al-Kuri. More recent studies focussed on specific taxonomic, systematic and ecological issues of Socotra's macroalgal flora (Kemp 1998a, Wynne \& Leliaert 2001, Schils \& Coppejans 2002, Schils et al. 2002). In an effort to protect the marine and terrestrial natural heritage of the archipelago (United Nations Development Programme for the Sustainable Use and Conservation of the Socotra Archipelago), an interdisciplinary team of scientists studied the vulnerable ecosystems and endangered species around the archipelago. Their work highlighted the diversity and the pristine nature of the marine habitats. The present study is an ecological follow-up and aims to identify the main plant communities around these islands, analysing their species composition and biogeographic affinities.

\section{MATERIALS AND METHODS}

Macroalgal and seagrass communities around the Socotra Archipelago were sampled in spring 2000 (26 March to 7 May). A total of 82 vegetation quadrats from 21 sites (Fig. 1, Appendix 1) were used to compare the different algal assemblages of the main island, Abd al-Kuri and Samha. At each site homogeneous macroalgal assemblages on subtidal platforms, ranging from 5 to $15 \mathrm{~m}$ below the surface, were selected; here the quadrats $\left(0.25 \mathrm{~m}^{2}\right)$ were randomly placed. Upon recording the species using BraunBlanquet's combined estimation (Table 1), the quadrats
Table 1. Braun-Blanquet's combined estimation and the transformed scale of Braun-Blanquet (van der Maarel 1979, Schaminée et al. 1995)

\begin{tabular}{|c|c|c|c|}
\hline \multirow[t]{2}{*}{$\begin{array}{l}\text { Estimate of } \\
\text { individuals }\end{array}$} & \multicolumn{2}{|c|}{$\begin{array}{c}\text { Braun-Blanquet's } \\
\text { combined estimation }\end{array}$} & \multirow{2}{*}{$\begin{array}{c}\text { van der } \\
\text { Maarel } \\
\text { Code }\end{array}$} \\
\hline & Cover $(\%)$ & Code & \\
\hline Rare & $<5$ & $\mathrm{r}$ & 1 \\
\hline Few & $<5$ & + & 2 \\
\hline Many & $<5$ & 1 & 3 \\
\hline Abundant & $<5$ & 2 & 4 \\
\hline Arbitrary & $5-25$ & 2 & 4 \\
\hline Arbitrary & $25-50$ & 3 & 5 \\
\hline Arbitrary & $50-75$ & 4 & 6 \\
\hline Arbitrary & $>75$ & 5 & 7 \\
\hline
\end{tabular}

were cleared and the algae were gathered in finemesh plastic bags. In the field laboratory, the bags were sorted by species, and fresh weight was measured with a dynamometer. Small and crustose algae were excluded from the analyses as their biomass is hard to determine and a meticulous investigation of the whole substratum and epiphytes is too timeconsuming. Representative specimens were pressed to become herbarium specimens, preserved in $5 \%$ formaldehyde-seawater solution or dried in silica gel for molecular studies. The reference collection is lodged in the Ghent University herbarium.

Ordination. Biomass data were selected as the most informative ordination input. Before ordination, biomass data were log-transformed and rare species were downweighted. Detrended Correspondence Analysis (DCA performed with CANOCO; ter Braak 1988) was chosen as an indirect gradient analysis because: (1) the data clearly represent a unimodal model (maximum gradient length, 7.615 SD; ter Braak \& Šmilauer 1998) and (2) the Correspondence Analysis (CA) showed a pronounced arch effect.

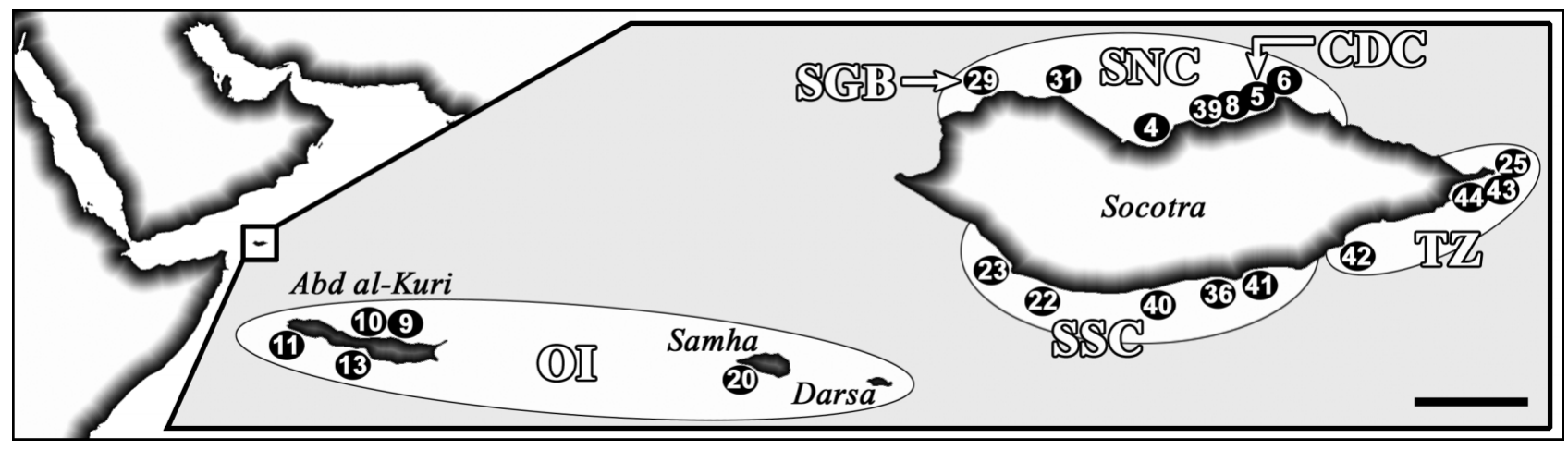

Fig. 1. Geographic position of the Socotra Archipelago showing sampling sites $(\bullet$, numbers indicate the sites where quadrats were cleared during the marine surveys of the 6EF project on the biodiversity of the Socotra Archipelago) and 6 DCA (Detrended Correspondence Analysis) clusters. SGB: seagrass beds, CDC: coral-dominated communities, SNC: Socotra's north coast, TZ: transition zone, SSC: Socotra's south coast, OI: outer islands. Scale bar $=25 \mathrm{~km}$ 
In an attempt to determine the species-environment correlation, environmental data around Socotra (latitude 9.650 to $14.383^{\circ} \mathrm{N}$; longitude 51.900 to $57.067^{\circ} \mathrm{E}$ ) were obtained from the Worldwide Ocean Optics Database (http://wood.jhuapl.edu, WOOD version 4.0). Chlorophyll a (CHL), nitrate $\left(\mathrm{NO}_{3}\right)$, nitrite $\left(\mathrm{NO}_{2}\right)$, oxygen $\left(\mathrm{O}_{2}\right)$, phosphate $\left(\mathrm{PO}_{4}\right)$, salinity $(\mathrm{SAL})$, silicate $\left(\mathrm{SiO}_{4}\right)$ and temperature (TMP) parameters showed a good sample distribution for the area. All these parameters were sampled for the SW monsoon (Julian Days 121 to 304) and the NE monsoon (Julian Days 305 to 120) and the average of each parameter during each period was calculated for 3 geographic areas around the archipelago (Zone 1: $>12.335^{\circ} \mathrm{N}$, Zone $2:<12.335^{\circ} \mathrm{N}$ and $>53.835^{\circ} \mathrm{E}$, Zone 3 : $<12.335^{\circ} \mathrm{N}$ and $<53.835^{\circ} \mathrm{E}$ ). The water masses of these 3 areas affect the greater part of the coastal waters with respect to their physico-chemical properties. Additional parameters were derived from the original data, i.e. the absolute difference in a parameter between the 2 monsoon periods (environmental parameter_AD) and the average between the periods (parameter_AV). Thus, this environmental data set has identical parameter values for all sites of a specific area (corresponding with the DCA clusters). To tackle this lack of resolution in the environmental data, a pseudo-environmental data set, composed of the latitude (LAT_N) and longitude (LON_E) coordinates of the quadrats, was used. The idea was that the correlation between species occurrences and the geographic coordinates of their sampling sites might be indicative of environmental gradients that vary according to the geographic position around the archipelago. All parameters were standardized to zero mean and unit variance.

Less informative ordination inputs, species records in a van der Maarel scale (deduced from the BraunBlanquet cover data, Table 1) and species presence or absence, were tested against the ordination results of the biomass data for each species within a quadrat.

Statistics. Subsequent analyses of the DCA clusters (plant communities) included the calculation of species richness per quadrat, total biomass per quadrat, alpha diversity per quadrat (BioDiversity Professional Version 2: Fisher's log-series alpha, Fisher et al. 1943) and beta diversity (Jaccard similarity coefficient as a qualitative index: $S J=a(a+b+c)^{-1}$ where $a=$ no. of species shared between 2 clusters, $b=$ no. of species restricted to the first cluster and $c=$ no. of species restricted to the second cluster; similarity ratio as a quantitative index: $S R_{i j}=\sum_{k} y_{k i} y_{k j}\left[\sum_{k} y_{k i}{ }^{2}+\sum_{k} y_{k j}{ }^{2}-\sum_{k} y_{k i} y_{k j}\right]^{-1}$, where $y_{k i}=$ biomass of species $k$ in cluster $i$ and $y_{k j}=$ biomass of species $k$ in cluster $j$ ). Species richness was square root $^{-1}$-transformed, total biomass and Fisher's alpha were natural log-transformed prior to variance analysis in order to achieve normality and homogeneity of variances. ANOVAs with the Tukey HSD test (Zar 1996) for post hoc multiple comparisons were performed with SPSS for Windows 11.0.1 (SPSS 2001).

Biogeography. The biogeographic affinities of Socotra's subtidal plant communities are analyzed by comparing the species composition of the DCA clusters to species inventories of Indian Ocean countries. The latter data set is primarily based on Silva et al. (1996) and supplemented with records from recent papers. The floristic affinity of a cluster with a specific country is calculated as the Simpson similarity coefficient: $\mathrm{SS}=a(a+\min [b, c])^{-1} \times 100$, where $a$ is the number of shared species between a cluster and a country and $b$ and $c$ are the numbers of species unique to the cluster and the country, respectively. The species inventories of clusters are always smaller than those of countries; thus the equation does not include the floristic richness of a country, as it is irrelevant in a study restricted to subtidal surveys and it reduces the discrepancy of sampling efforts between different countries. The countries are arranged from SE Africa, over the Arabian Sea, to Western Australia. India was excluded from the series as its size and geographic position cover a wide diversity of floras within the Indian Ocean.

\section{RESULTS}

\section{Species count}

A total of 127 plant species (3 seagrasses, Magnoliophyta; 29 Chlorophyta; 26 Phaeophyta; 69 Rhodophyta) are recorded for the 82 subtidal quadrats (Appendix 2). This corresponds to a Cheney's ratio (the sum of the Rhodophyceae and Chlorophyceae divided by the no. of Phaeophyceae) of 3.8 .

\section{Ordination}

The DCA of the biomass data of the 82 quadrats shows 6 distinct site groupings (Fig. 2), which correspond well with their geographic position around the archipelago (Fig. 1). Both axes have high eigenvalues (0.781 and 0.688 ) and together they represent $14.8 \%$ of the variation in species composition. The plot reflects the geographic position of the sample stations within the archipelago, presumably relating to the physicochemical characteristics of the water mass. This is shown in the high correlation of the latitude coordinates $(-0.7285)$ with the first DCA axis and the longitude $(0.4514)$ with the second DCA axis. Both axes have a large length of gradient (7.442 and 6.860), indicating the high beta-diversity between the quadrats of the different communities. The following clusters can be 


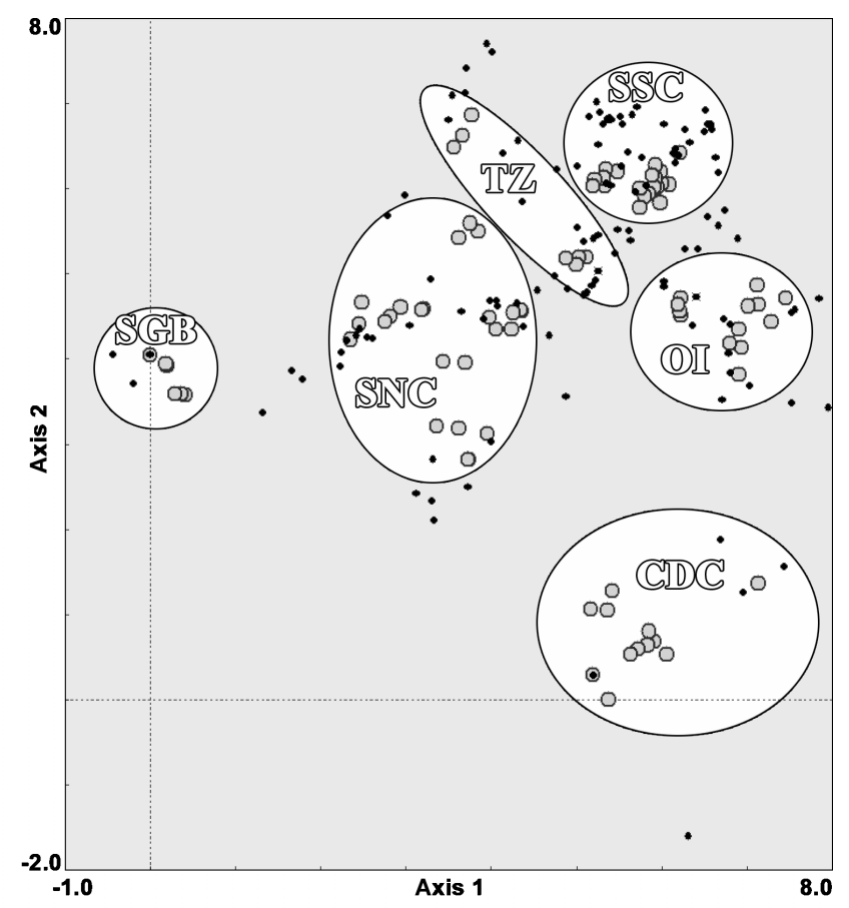

Fig. 2. First 2 ordination axes of a DCA based on logtransformed biomass data of subtidal macroalgae and seagrasses (black dots) in different quadrats (filled circles); rare species are downweighted. See Fig. 1 for cluster abbreviations

discerned (Fig. 2): the seagrass beds (SGB), the coral dominated communities (CDC), Socotra's north coast (SNC), the transition zone at the eastern extremity of Socotra Island (TZ), Socotra's south coast (SSC), and the outer islands (OI). The DCA shows a gradual change in species composition from SNC, over TZ, to SSC. SSC is characterized by a high number of species, many restricted to this zone of the archipelago (the aggregation of species around SSC in the biplot, Fig. 2). OI constitutes a distinct cluster, intermediately positioned along the gradient from $\mathrm{SNC}$, over $\mathrm{TZ}$ to $\mathrm{SSC}$. The quadrats of SGB and CDC also constitute 2 distinct clusters in the DCA. The plant communities of these 2 clusters differ substantially in species composition, biomass and species richness from the other DCA clusters, potentially distorting the affinities of the remaining quadrats, hence their exclusion in the subsequent DCA.

The second DCA (Axes 1 and 2, respectively: eigenvalues, 0.732 and 0.469 ; lengths of gradient, 5.513 and 3.876; cumulative \% variance of species data, 9.6 and $15.7)$ revealed the same clusters as the previous analysis (Fig. 3). However, the quadrat clusters are less geographically distributed in the biplot compared with the first DCA: high correlation of longitude (0.743) and latitude (0.490) coordinates with the first DCA axis and low correlation (0.199 and 0.291 , respectively) with the second DCA axis. The difference between SNC, SSC

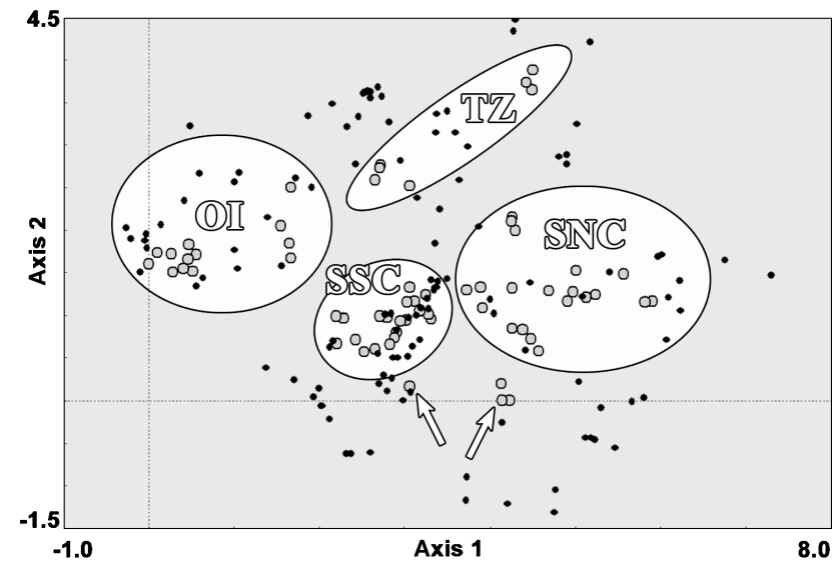

Fig. 3. First 2 ordination axes of the second DCA in which the quadrats of SGB and CDC are excluded. Ordination based on log-transformed biomass data; rare species are downweighted. See Fig. 1 for cluster abbreviations. Arrows indicate a few quadrats of the north coast of Abd al-Kuri that group with SNC in the first DCA (see Fig. 2)

and OI is principally determined by the first DCA axis. Relative to the first axis, TZ and a few quadrats of the north coast of Abd al-Kuri (ANC, Fig. 3, arrows) are intermediate between SSC and SNC. The second axis mainly discerns SNC and SSC from OI and TZ. The second axis might be interpreted as the variability in current velocity and direction within a season: velocities are very high and the direction is rather irregular at TZ, somewhat less variable at OI, and more regular (although seasonally variable) at SSC and SNC. The low value of ANC for the second axis corresponds with the sheltered position of the site. This diversity in current patterns around the archipelago shapes the substratum (steep rocky shorelines with numerous microhabitats, e.g. crevices, sand deposition), which in turn determines algal composition.

Table 2 shows that most variables have markedly higher (absolute) correlation values with the first DCA axis (parameters $\mathrm{PO}_{4} \_\mathrm{SW}$ to $\mathrm{CHL} \_\mathrm{NE}$ ). Certain parameters, however, correlate better with the second axis: $\mathrm{SiO}_{4} \_\mathrm{SW}(-0.547), \mathrm{SiO}_{4} \_\mathrm{AD}(-0.547), \mathrm{O}_{2} \_\mathrm{SW}$ (0.544), $\mathrm{SiO}_{4} \_\mathrm{NE}$ (0.541). Most of the averages of both monsoon parameters (parameters with the _AV suffix) correlate well with both axes. The communities of SNC are separated from SSC along the first axis, which might result from the lower $\mathrm{PO}_{4}$ concentrations, the higher salinity and the higher temperatures of the former cluster during the SW monsoon. On the other hand, the $\mathrm{PO}_{4}$ concentrations during the NE monsoon are higher at SNC than SSC. The difference between these clusters can also be explained by the lower $\mathrm{PO}_{4}$, lower temperature and higher $\mathrm{O}_{2}$ fluctuations (_AD suffix) at SNC in comparison to SSC and OI. The separation along the second axis, e.g. TZ from SSC and SNC, might be caused 
Table 2. Correlation coefficients of the environmental parameters with the first 2 axes of the DCA. Absolute coefficient values in decreasing order for the first axis. For explanations of parameter abbreviations see text

\begin{tabular}{|c|c|c|c|c|c|}
\hline Parameter & Axis 1 & Axis 2 & Parameter & Axis 1 & Axis 2 \\
\hline $\mathrm{PO}_{4 \_} \mathrm{SW}$ & -0.7650 & -0.0997 & $\mathrm{NO}_{3 \_} \mathrm{AD}$ & -0.7146 & -0.2765 \\
\hline $\mathrm{PO}_{4 \_} \mathrm{AD}$ & -0.7648 & -0.0722 & CHL_AD & -0.7135 & -0.2784 \\
\hline SAL_SW & 0.7628 & 0.1315 & SAL_AD & -0.6893 & 0.1533 \\
\hline TMP_SW & 0.7610 & 0.1452 & $\mathrm{NO}_{3 \_} \mathrm{SW}$ & -0.6831 & -0.3230 \\
\hline $\mathrm{PO}_{4 \_} \mathrm{NE}$ & 0.7608 & 0.0313 & CHL_NE & 0.6440 & 0.3667 \\
\hline TMP_AD & -0.7567 & -0.0085 & $\mathrm{NO}_{3 \_} \mathrm{AV}$ & -0.5833 & -0.4173 \\
\hline $\mathrm{NO}_{3} \_\mathrm{NE}$ & 0.7493 & -0.0216 & $\mathrm{PO}_{4} \_\mathrm{AV}$ & -0.5770 & -0.4218 \\
\hline $\mathrm{O}_{2} \_\mathrm{AV}$ & 0.7473 & -0.0283 & SAL_AV & 0.5351 & 0.4481 \\
\hline $\mathrm{O}_{2 \_} \mathrm{AD}$ & 0.7445 & -0.0373 & $\mathrm{NO}_{2} \_\mathrm{SW}$ & -0.5046 & 0.3462 \\
\hline $\mathrm{O}_{2 \_} \mathrm{NE}$ & 0.7437 & -0.0396 & LON_E & 0.4904 & 0.2910 \\
\hline LAT_N & 0.7433 & 0.1990 & $\mathrm{SIO}_{4 \_} \mathrm{AV}$ & -0.4830 & -0.4748 \\
\hline NO2_AD & 0.7357 & -0.0621 & TMP_AV & 0.4666 & 0.4820 \\
\hline CHL_SW & -0.7339 & -0.2386 & SAL_NE & -0.3112 & 0.4561 \\
\hline $\mathrm{NO}_{2} \_\mathrm{NE}$ & 0.7339 & -0.0666 & $\mathrm{SIO}_{4} \_\mathrm{SW}$ & -0.1278 & -0.5466 \\
\hline $\mathrm{NO}_{2} \_\mathrm{AV}$ & 0.7330 & -0.0688 & $\mathrm{SIO}_{4 \_} \mathrm{AD}$ & -0.1193 & -0.5466 \\
\hline TMP_NE & -0.7293 & 0.0777 & $\mathrm{O}_{2} \_\mathrm{SW}$ & 0.0488 & 0.5438 \\
\hline CHL_AV & -0.7203 & 0.0975 & $\mathrm{SIO}_{4-\mathrm{NE}}$ & 0.0136 & 0.5407 \\
\hline
\end{tabular}

high eigenvalues ( 0.743 and 0.689$)$ and together they represent $15.7 \%$ of the variation in species composition. The DCA of the nominal data (presence/ absence) also shows a similar cluster pattern (Fig. 5), but the distinction between SNC, TZ, SSC and OI is less clear (intermingled quadrats) and this group of clusters constitutes a more homogeneous entity in relation to $\mathrm{CDC}$ and SGB. The first 2 axes of the latter DCA have high eigenvalues ( 0.707 and 0.589 ) and together they represent $12.4 \%$ of the variation in species composition.

\section{Species richness and biomass}

The ANOVA of the transformed species richness per quadrat shows 2 groups of DCA clusters (Fig. 6a):

by rather low $\mathrm{SiO}_{4}$ and high $\mathrm{O}_{2}$ concentrations (intense current patterns) at TZ during the SW monsoon, and high $\mathrm{SiO}_{4}$ concentrations at TZ during the NE monsoon. The fluctuations in $\mathrm{SiO}_{4}$ concentrations are higher at SSC than at TZ.

The DCA based on the van der Maarel data (Fig. 4) resulted in similar clusters but has less resolution, as the quadrats of TZ are partly grouped in SSC and SNC, respectively. The first 2 axes of this ordination have

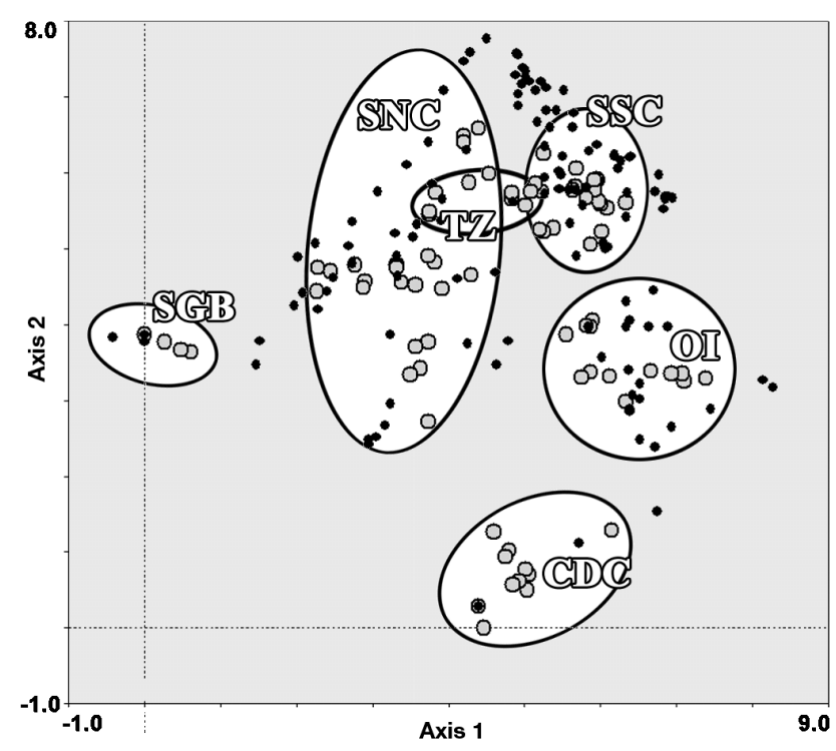

Fig. 4. First 2 ordination axes of a DCA based on cover data (van der Maarel scale) of subtidal macroalgae and seagrasses (black dots) in different quadrats (filled circles), rare species are downweighted. See Fig. 1 for cluster abbreviations
(1) SGB and CDC, characterized by a low floristic species richness; and (2) a second group incorporating the remaining clusters. The range of species richness per quadrat within the latter group varies highly, but the species richness of these clusters does not differ significantly. The highest number of species (31) per quadrat is reported for $\mathrm{TZ}$.

The ANOVA of the biomass data shows a group of clusters (SNC, TZ and SSC) with comparable bio-

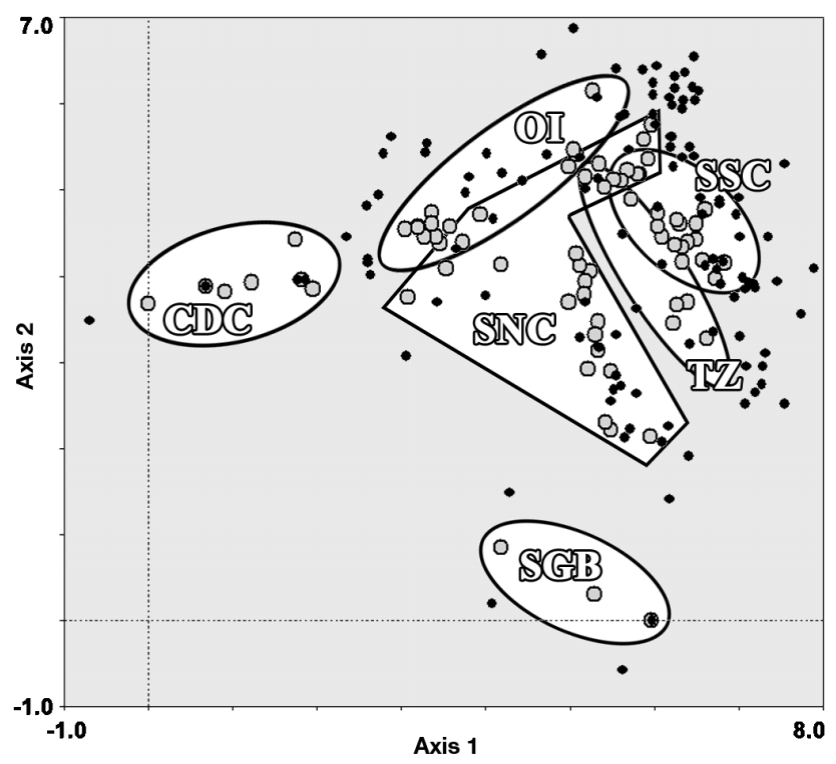

Fig. 5. First 2 ordination axes of a DCA based on presence/ absence data of subtidal macroalgae and seagrasses (black dots) in different quadrats (filled circles). See Fig. 1 for cluster abbreviations 

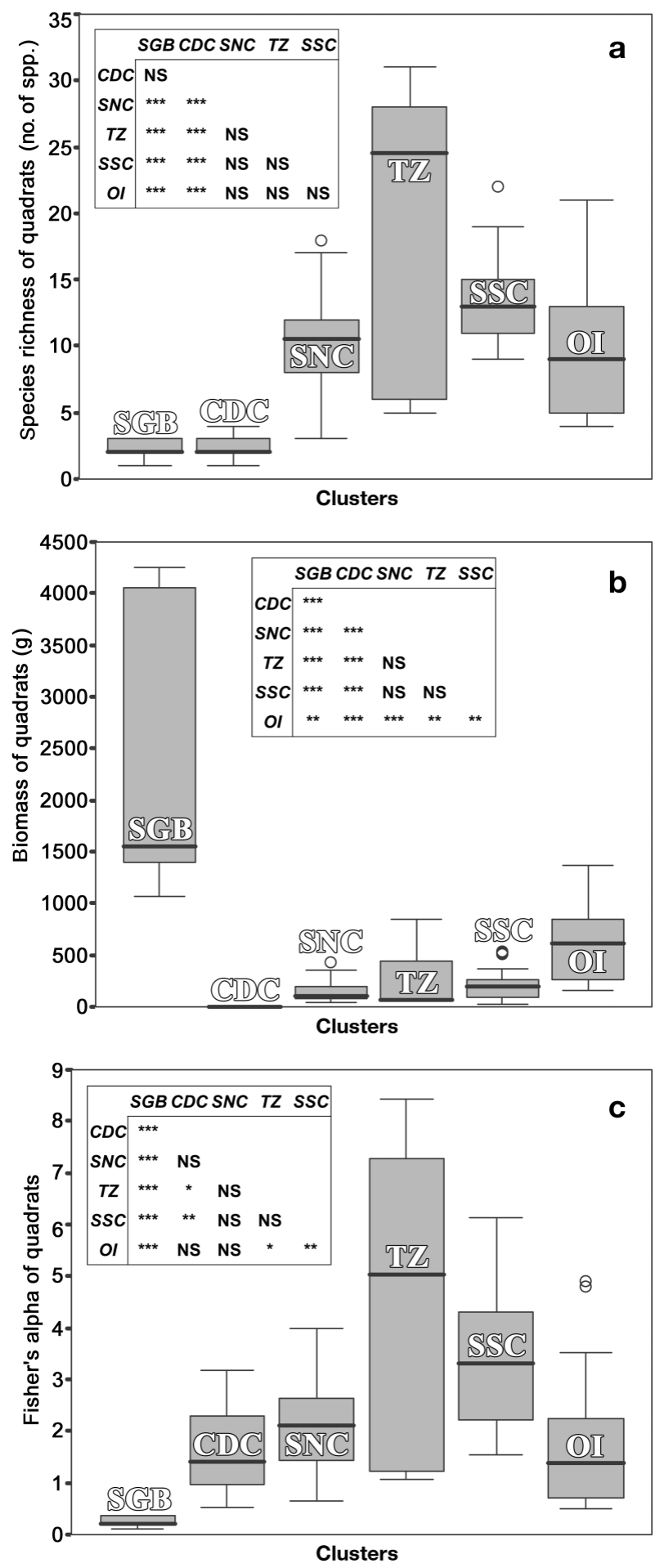

Fig. 6. Box plots of (a) species richness, (b) total biomass and (c) Fisher's alpha diversity of quadrats (untransformed) showing median, quartiles and extreme values for each DCA cluster (see Fig. 1 for cluster abbreviations). Number of quadrats in each cluster: SGB (6), CDC (12), SNC (24), TZ (10), SSC (17), OI (13). Open circles denote outliers. Insets: ANOVA, Tukey HSD of (a) square root $^{-1}$-transformed and $(\mathrm{b}, \mathrm{c})$ natural log-transformed data. NS $=$ not significant; ${ }^{*} \mathrm{p}<0.05$;

$$
{ }^{* *} \mathrm{p}<0.01 ; * * * \mathrm{p}<0.001
$$

masses (Fig. 6b). TZ has the widest interquartile range, encompassing that of SNC and SSC. The quadrats of the SNC and SSC clusters have intermediate biomasses between those of SGB, expressing the highest biomass per quadrat, and those of $\mathrm{CDC}$, characterized by the lowest biomass. OI differs significantly from the group of clusters described above, but the quadrats of OI are also characterized by biomass values intermediate between, and differing substantially from, those of SGB and CDC.

\section{Alpha and beta diversity}

The log-series variable alpha, composite index of species richness and abundance, shows the highest species diversity per quadrat for the most species-rich clusters with moderate biomass (high evenness), i.e. TZ and SSC (Fig. 6c). A second group, consisting of CDC and OI, shows a significantly lower alpha diversity than the TZ-SSC group. SNC has an intermediate alpha diversity between these groups, as it does not differ significantly from any of the 4 clusters. SGB is characterized by the lowest alpha diversity values.

The Jaccard similarity coefficient, as a qualitative measurement for beta-diversity (Table 3 ), shows that

Table 3. Jaccard similarity coefficient (\%) as a qualitative measurement for beta-diversity among the DCA clusters (SGB: seagrass beds, CDC: coral dominated communities, SNC: Socotra's north coast, SSC: Socotra's south coast, TZ: transition zone, OI: outer islands). Similarities higher than 10 are marked in bold

\begin{tabular}{|lrrrrr|}
\hline & SGB & CDC & SNC & TZ & SSC \\
\hline CDC & 0.00 & & & & \\
SNC & 3.57 & 3.45 & & & \\
TZ & 1.82 & 1.75 & $\mathbf{2 4 . 7 1}$ & & \\
SSC & 1.16 & 2.30 & $\mathbf{2 8 . 0 4}$ & $\mathbf{4 0 . 6 3}$ & \\
OI & 0.00 & $\mathbf{1 0 . 2 6}$ & $\mathbf{1 3 . 7 5}$ & $\mathbf{2 1 . 9 2}$ & $\mathbf{2 6 . 3 2}$ \\
\hline
\end{tabular}

Table 4. Similarity ratio as a quantitative measurement for beta-diversity among the DCA clusters (SGB: seagrass beds, CDC: coral dominated communities, SNC: Socotra's north coast, SSC: Socotra's south coast, TZ: transition zone, OI: outer islands). The high similarity values of TZ with SSC and $\mathrm{SNC}$, respectively, are marked in bold

\begin{tabular}{|lcrrrr|}
\hline & SGB & CDC & SNC & TZ & SSC \\
\hline CDC & 0.00 & & & & \\
SNC & 0.04 & 3.97 & & & \\
TZ & 0.01 & 0.01 & $\mathbf{6 4 . 8 1}$ & & \\
SSC & 0.00 & 0.00 & 1.62 & $\mathbf{8 0 . 7 6}$ & \\
OI & 0.00 & 0.00 & 0.45 & 0.02 & 3.13 \\
\hline
\end{tabular}


SSC and TZ are the most similar DCA clusters (lowest degree of species turnover). Both are somewhat less similar to the communities of SNC and OI. The quantitative similarity ratio is less resolving (Table 4). In addition to the high similarity in absolute species composition, the species occurring at $\mathrm{TZ}$ have a comparable biomass to those at SSC and SNC. However, SSC and SNC show a low quantitative similarity to each other, illustrating the intermediate nature of TZ.

\section{Biogeography}

The graphs of the biogeographic affinity of the DCA clusters within the Indian Ocean show 3 general trends (Fig. 7), corresponding with the following coastal areas: (1) South Africa to Kenya (east African coast); (2) Kenya to Iran (Arabian Sea); (3) Iran to Western Australia (eastern Indian Ocean). CDC showed an additional trend for the eastern Indian Ocean: an increase in affinity for the region Pakistan to Sri Lanka and a plateau for Sri Lanka to Western Australia. For each of these coastal blocks the regression lines were calculated in order to compare the general trends of the different clusters (Schils et al. 2001). SGB and CDC are composed of common Indian Ocean taxa, visualized by an increasing affinity for the east African flora from South Africa to a peak in Kenya. Thereafter, the affinity decreased for the Arabian Sea, the result of a few unrecorded common Indian Ocean taxa for this area. These species, e.g. Dictyosphaeria cavernosa (Forsskål) Børgesen, are probably ubiquitous throughout the Arabian Sea as they have already been reported for the Arabian Gulf (De Clerck \& Coppejans 1996). Similar patterns were obtained for SNC, TZ and $\mathrm{SSC}$, with a decreasing overall affinity in this order (Fig. 7a). OI appeared like a combination of the other clusters, having a relatively high affinity with the east African coast (common Indian Ocean taxa) similar to SNC, a decreasing affinity with the Arabian Sea flora (an artefact of undersampling in the Arabian Sea) like CDC and a relatively low affinity with the eastern Indian Ocean comparable to SSC (Fig. 7b).

\section{DISCUSSION}

The Cheney ratio has been used to correlate macroalgal floras with seawater temperature (Cheney 1977, Bolton 1986). The overall ratio for the archipelago is 3.8, which is indicative of a warm temperate flora (Kapraun 1980). The Cheney ratios of the major quadrat clusters (SNC, TZ, SSC and OI) are comparable, due to similar proportions of Chlorophyceae, Phaeophyceae and Rhodophyceae in these communities (Fig. 8). 


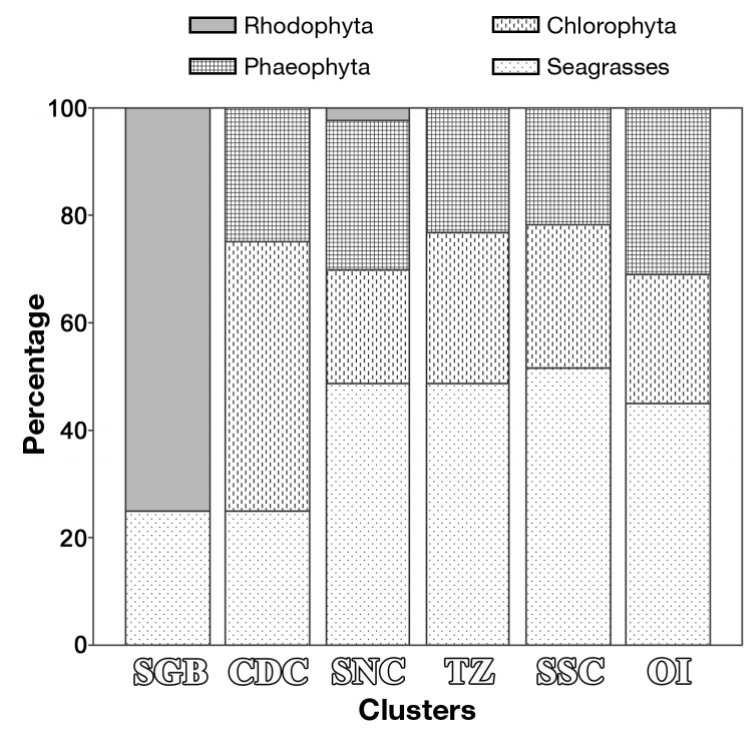

Fig. 8. Percentage of Rhodophyta, Phaeophyta, Chlorophyta and seagrasses in DCA clusters. See Fig. 1 for cluster abbreviations

The clusters obtained from the DCA can be grouped geographically, which is shown by the high correlation of the GIS coordinates to the first 2 DCA axes. The 6 clusters include distinct entities (SGB, CDC, SNC and SSC) and intermediate ones (TZ and OI). The characteristics of each of the subtidal plant communities are discussed below.

\section{Seagrass beds and coral-dominated communities}

SGB and CDC are characterized by a low floristic richness. Both clusters, however, can be regarded as subentities of Socotra's north coast as they occur in specialized habitats within SNC. The communities of these 2 biotopes differ substantially in species composition, biomass and species richness from the other DCA clusters and were excluded from the second DCA, in which the environmental variables were tested. Extensive seagrass beds are rather rare around the archipelago: patches of Halodule uninervis (Forsskål) Ascherson are scattered around the north coast (sandy substrate); well-developed Thalassodendron ciliatum (Forsskål) den Hartog beds occur in Mahfirhin Bay (Fig. 1, close to Site 42, no quadrats available); and extensive seagrass beds, composed of Halodule uninervis and Halophila ovalis (R. Brown) Hooker and Thalassia hemprichii (Ehrenberg) Ascherson are found in the Qalansiyah lagoon (Fig. 1, Site 29). Owing to the exclusion of small epiphytes in this study, SGB is species-poor but shows the greatest standing stock of all community types. With respect to other seagrass communities, generally consisting of 1 or 2 seagrass species (Duarte 2000), Qalansiyah lagoon, however, contains plant communities with a moderate seagrass richness (3 species).

CDC is typified by a predominant coral cover (>90\%) complemented with some common Indian Ocean algae characteristic of this habitat, e.g. Chlorodesmis fastigiata (C. Agardh) Ducker and Dictyota friabilis Setchell. Coral reef development is restricted to small patches around the archipelago. Coral reef formation is rare within the Arabian Sea, and the phenomenon of large monotypic reefs (e.g. the Montipora reefs at Masirah Island, Oman) shows that the environmental conditions are generally too harsh and unfavourable for many coral species (Coles 1995, Paulay 1999, Wilson 2001). Recent field studies have, however, demonstrated that the area hosts more coral species and endemics than previously thought (Paulay \& Meyer 2001).

\section{Socotra's north coast}

The north coast of Socotra is typified by a mixture of well-developed coral assemblages (e.g. CDC at Hawlaf; Fig. 1, Site 5) and algal communities (e.g. Diham; Fig. 1, Site 4). The marine macroflora of this area consists mainly of common east African/Indian Ocean taxa, reflected in the high general affinity with the Indian Ocean flora (Fig. 7a). The environmental correlations show that this cluster is characterized by the highest water temperatures and salinities of the archipelago during the SW monsoon. SNC has the highest values of the low $\mathrm{PO}_{4}$ concentrations during the NE monsoon. During the SW monsoon, the $\mathrm{PO}_{4}$ concentrations are higher with the lowest values for SNC. Consequently, this entity is characterized by the smallest changes in $\mathrm{PO}_{4}$ concentrations and temperature, the lowest average chlorophyll a concentrations, and the highest average $\mathrm{O}_{2}$ concentrations. A total of 43 species were collected in the subtidal quadrats of this area. The species richness per quadrat does not differ from SSC, TZ and OI, and the alpha diversity is intermediate in terms of all communities around the archipelago. The biomass of the quadrats equals those of TZ and SSC. The communities of SNC have a high similarity in structural composition (quantitative beta-diversity) with TZ (64.81) and show a high qualitative similarity with SSC (28.04) and TZ (24.71). SNC and SSC thus share a relatively high number of species, partly due to the high number of recorded species for SSC, but these occur throughout both clusters in low abundances. 


\section{Socotra's south coast}

During the SW monsoon, the Great Whirl (extending northwards along the Somali coast) spins off towards Socotra's south coast (http://www.nioz.nl/ en/facilities/dmg/niop/themes/theme-c/thmchydr). This cold and nutrient-rich surface water $\left(\sim 22^{\circ} \mathrm{C}\right)$ shapes the southern coast of Socotra. The impact of upwelling hampers coral development (e.g. bioerosion, Paulay 1999) and promotes macroalgal growth in an ongoing competition with the coral communities due to the favourable environmental parameters during the monsoon (e.g. high $\mathrm{PO}_{4}$ concentrations and low temperature). Consequently, the SSC vegetation is relatively high in biomass and rich in species, resulting in high alpha diversity values. In addition, SSC contains the largest number of species per cluster (64). The flora comprises a large number of red algal species that generally contribute little to the total biomass in understory layers, e.g. Zellera tawallina G. Martens, and more to the primary layer, e.g. large plants of Botryocladia leptopoda (J. Agardh) Kylin. In addition, a remarkable number of gelatinous red algae (Schils \& Coppejans 2002) have been reported for this area. Despite the relatively high number of species recorded for the quadrats, the biogeographic affinity within the Indian Ocean is low. This is the result of a number of disjunctly distributed and endemic species (Schils et al. 2002, Schils \& Huisman 2003), reflecting biogeographic affinities with distant areas (Australia, Hawaii, Japan and South Africa). Børgesen (1934) and Wynne (2000) noted similar distribution patterns for certain species within the Pakistani and Omani flora, respectively. The disjunct distribution pattern of these algae could result from: (1) the upwelling phenomenon and the resulting peculiar environmental conditions; (2) refugia where algae could persist subtidally over a long time (e.g. Reticulocaulis, Schils et al. 2002, Millar \& Kraft 1984); (3) the lack of subtidal studies in the Indian Ocean. Similar disjunct distribution patterns have also been reported for coral species from the Arabian Sea (Coles 1995).

\section{Transition zone}

The algal communities at the eastern extremity of Socotra Island are characterized by high biomass stands, being rich in species (species richness of the quadrats). This results in the highest alpha diversity values of all surveyed sites around the archipelago. The total number of recorded species in this cluster (39) is somewhat lower than that of SSC and SNC, most probably a result of the low number of quadrats (10) included in TZ. The communities are composed of a mixture of primarily south coast species (highest qualitative and quantitative similarities) and north coast species. The macroalgal stand (biomass) is similar to that of SNC and SSC. We can conclude that the transition zone is a gradual overlapping zone between the communities of Socotra's north and south coast. This cluster is, however, also characterized by certain algae (e.g. Gibsmithia larkumii Kraft and Sympodothamnion sp., authors' pers. obs.), displaying a disjunct distribution pattern within the Indo-Pacific. This is reflected in the biogeographic graph (Fig. 7a), in which TZ, compared to $\mathrm{SNC}$, shows a decline in the general affinity with Indian Ocean taxa. The floristic peculiarity of this cluster is most probably related to the prevailing environmental conditions. The eastern tip of Socotra Island is subject to upwelling and in addition there seems to be a pronounced effect of the Socotra eddy evolving east from the island, contiguous with the other anticyclonic circulation the 'Great Whirl' (http://www.ssc. erc.msstate.edu/Altimetry/north_indian_ocean.html). Complex and intense current patterns were noted here, and local fishermen cannot access this area during the greater part of the SW monsoon (authors' pers. obs.). Presumably, these intense currents favour the luxuriant and particularly red algal flora that occurs here, due to the constant flow of nutrients and the temperature regulation of these subtidal habitats (corresponding to the position of TZ along the first DCA axis, between SSC and SNC). Unfortunately, data of current patterns and velocities were not available for inclusion in the analysis.

\section{Outer islands}

The outer islands of this study include Abd al-Kuri and Samha Island. There were no quadrat data from Darsa Island available, but based on its geographic position the communities are likely to be similar to those of OI. Certain quadrats of the north coast of Abd al-Kuri (ANC) group with SNC in the first DCA, but this is less pronounced in the second DCA (arrows in Fig. 3). This supports the hypothesis for a drive towards the development of macroalgal communities comparable to those of the main island (SNC and SSC), but this climax stage is not reached due to the drastically changing chemical characteristics and water dynamics around a small coastal area (area effect). Support for these speculations can be found in the second DCA, where OI is positioned close to the origin of the first axis, which is highly negatively correlated with the fluxes in $\mathrm{PO}_{4}$ concentrations and temperature. This is backed by $\mathrm{J}$. van Bennekom, T. de Bruin and J. Nieuwenhuis (http://www.nioz.nl/en/facilities/dmg/ 
niop/themes/theme-c/thmchydr), who state that the region between Socotra and Ras Fartak shows alternating patches of relatively warm and cold surface water. Likewise, J. C. van Ooijen and E. van Weerlee (http://www.nioz.nl/en/facilities/dmg/niop/themes/ theme-c/thmchydr) note that between Cap Guardafui and Socotra the entire water column is seasonally renewed to a depth of $1100 \mathrm{~m}$. The importance of the high environmental dynamics at OI has major ecological implications: Turner (http://www.cordio.org/ Repstatus10.htm) observed that the islands Samha and Darsa were barely affected by the coral bleaching that hit main Socotra severely in 1998. The mixed species composition is also reflected in the biogeographic trend, being composed of different biogeographic affinities characteristic of the other communities. Accordingly, OI is characterized by high abundances and diversity in coastal fish, soft corals and scleractinian corals, accounting for a large proportion of the archipelago's total diversity (DeVantier 2000, Reinicke et al. 2000, Zajonz et al. 2000).

\section{CONCLUSIONS}

The DCA of the van der Maarel data, a less timeconsuming field estimation in comparison to the biomass determinations of each species, reveals similar results to the biomass DCA. Using this methodology, it is still necessary to clear the quadrats in order to note the smaller and uncommon species that prove to be important in the analyses, e.g. Chauviniella coriifolia (Harvey) Papenfuss and Claudea elegans Lamouroux. The presence/absence data, on the other hand, obscure the patterns in community structure, and more elaborate data sets (checklists of larger areas, more samples, more zonation belts) are required to distinguish between the community types.

The strong correlation of the $\mathrm{PO}_{4}$ concentrations during the SW and NE monsoon with the first DCA axis agrees with the observation that $\mathrm{P}$, rather than $\mathrm{N}$, may be of paramount importance in limiting primary production of macroalgae in carbonate-rich waters (Lapointe et al. 1992). The relationship of the $\mathrm{SiO}_{4}$ concentration to the second DCA axis seems to be odd, as this indicator for upwelling does not differentiate between SNC and SSC. There are several possibilities to explain this anomaly: (1) upwelling is a coastal phenomenon but the included environmental data are averages of a broader area and the cycle in which the parameter varies from highs to lows might happen considerably more frequent than the 2 periods for which the data were averaged, so the resolution of the data set might be too low; (2) the $\mathrm{SiO}_{4}$ concentrations vary likewise in the different coastal waters and corre-

spond to a lesser extent with the vegetation differences around the archipelago; (3) a synergy of environmental variables might be important in shaping the macroalgal assemblages, obscuring the importance of $\mathrm{SiO}_{4}$ as an indicator for upwelling. Altogether, the oceanic data around the archipelago correspond well to the seasonal changes in environmental parameters reported for the southern Arabian shores and the resulting influence on its biotic communities (e.g. Ormond \& Banaimoon 1994). Besides these abiotic factors, biotic interactions or complex cascade effects are suspected as being important in shaping the subtidal communities, especially so for the species-rich outer islands with a limited coastal area.

Although the Socotra archipelago harbours a diversity of well-characterized subtidal communities, showing high affinities with a common Indian Ocean flora, its similarity with other communities within the upwelling-influenced Arabian Sea remains unclear as ecological macroalgal studies in this area are lacking. Another investigation that remains is the quantification of the relationship between the upwelling flora (disjunct species of SSC, TZ and OI) with distant regions such as Australia, Hawaii, Japan and South Africa.

Acknowledgements. Thanks are expressed to the Senckenberg Research Institute (M. Apel and F. Krupp) for the excellent field trip preparations to the Socotra Archipelago. We are grateful to Frederik Leliaert and Olivier De Clerck for their help in identifying Cladophorales and Dictyota specimens, respectively. Henry Engledow is gratefully acknowledged for his constructive comments on the manuscript. Tom Schils is indebted to the Fund for Scientific Research Flanders (FWO, Belgium) for his research assistant grant. The 4 anonymous referees are thanked for their constructive criticism.

Appendix 1. Coordinates of the 21 sample sites around the Socotra Archipelago

Site $\quad 4: 12.630^{\circ} \mathrm{N}, 53.869^{\circ} \mathrm{E}$ Site $5: 12.681^{\circ} \mathrm{N}, 54.077^{\circ} \mathrm{E}$ Site $6: 12.693^{\circ} \mathrm{N}, 54.085^{\circ} \mathrm{E}$ Site $8: 12.664^{\circ} \mathrm{N}, 54.045^{\circ} \mathrm{E}$ Site $9: 12.204^{\circ} \mathrm{N}, 52.259^{\circ} \mathrm{E}$ Site 10: $12.204^{\circ} \mathrm{N}, 52.273^{\circ} \mathrm{E}$ Site $11: 12.226^{\circ} \mathrm{N}, 52.073^{\circ} \mathrm{E}$ Site 13: $12.173^{\circ} \mathrm{N}, 52.226^{\circ} \mathrm{E}$ Site 20: $12.157^{\circ} \mathrm{N}, 52.985^{\circ} \mathrm{E}$ Site $22: 12.315^{\circ} \mathrm{N}, 53.623^{\circ} \mathrm{E}$ Site 23: $12.355^{\circ} \mathrm{N}, 53.544^{\circ} \mathrm{E}$
Site $25: 12.528^{\circ} \mathrm{N}, 54.540^{\circ} \mathrm{E}$ Site 29: $12.701^{\circ} \mathrm{N}, 53.500^{\circ} \mathrm{E}$ Site $31: 12.700^{\circ} \mathrm{N}, 53.654^{\circ} \mathrm{E}$ Site $36: 12.321^{\circ} \mathrm{N}, 53.919^{\circ} \mathrm{E}$ Site 39: $12.639^{\circ} \mathrm{N}, 53.944^{\circ} \mathrm{E}$ Site $40: 12.303^{\circ} \mathrm{N}, 53.843^{\circ} \mathrm{E}$ Site $41: 12.322^{\circ} \mathrm{N}, 54.034^{\circ} \mathrm{E}$ Site $42: 12.403^{\circ} \mathrm{N}, 54.243^{\circ} \mathrm{E}$ Site $43: 12.535^{\circ} \mathrm{N}, 54.513^{\circ} \mathrm{E}$ Site $44: 12.532^{\circ} \mathrm{N}, 54.520^{\circ} \mathrm{E}$ 
Appendix 2. Species recorded in quadrats, showing in which clusters they occurred. See text for cluster abbreviations

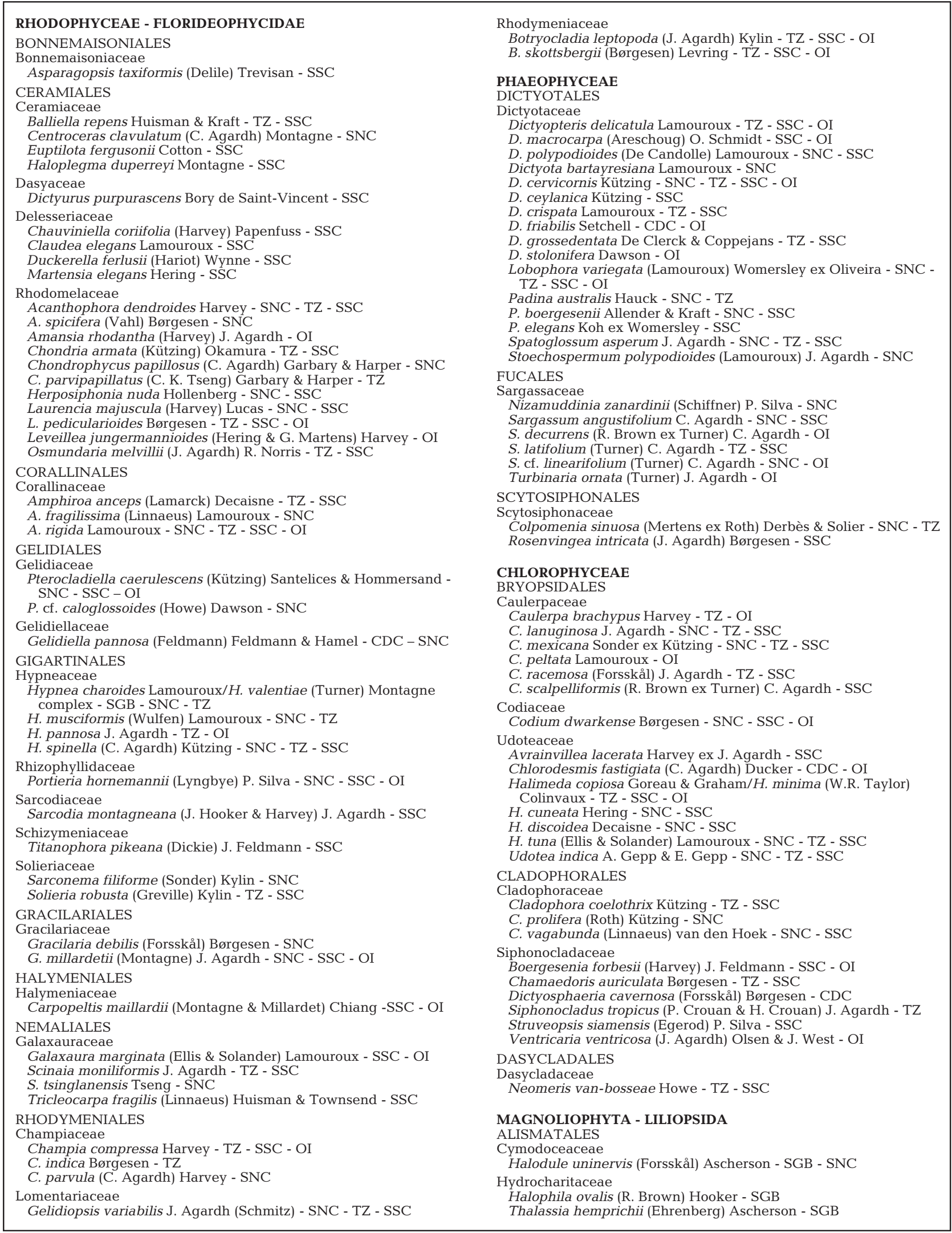




\section{LITERATURE CITED}

Bolton JJ (1986) Marine phytogeography of the Benguela upwelling region on the west coast of southern Africa: a temperature dependent approach. Bot Mar 14:251-256

Børgesen F (1934) Some marine algae from the northern part of the Arabian Sea with remarks on their geographical distribution. Biol Medd K Dan Vidensk Selsk 11:1-72

Cheney DF (1977) R \& C/P, a new and improved ratio for comparing seaweed floras. J Phycol 13(Suppl):12

Coles SL (1995) Corals of Oman. CYK Publications, Muscat

De Clerck O, Coppejans E (1996) Marine algae of the Jubail Marine Wildlife Sanctuary, Saudi Arabia. In: Krupp F, Abuzinada AH, Nader IA (eds) A marine wildlife sanctuary for the Arabian Gulf: environmental research and conservation following the 1991 Gulf War oil spill. NCWCD, Riyadh \& Senckenberg Research Institute, Frankfurt/M, p 199-289

DeVantier LM (2000) Coral communities of the Socotra Archipelago. In: Apel M, Hariri KI (eds) Conservation and sustainable use of biodiversity of Socotra Archipelago: marine habitat, biodiversity and fisheries surveys and management. Progress report of phase III. Senckenberg Research Institute, Frankfurt/M, p 49-80

Dickie G (1888) Algae. In: Balfour IB (ed) Botany of Socotra. Trans R Soc, Edinb, Vol 31. Robert Grant \& Son, Edinburgh, p 394-401

Duarte CM (2000) Benthic ecosystems: seagrasses. In: Levin SL (ed) Encyclopedia of biodiversity, Vol 5. Academic Press, San Diego, p 254-268

Fisher R, Corbet A, Williams C (1943) The relation between the number of species and the number of individuals in a random sample of an animal population. J Anim Ecol 12:42-58

Holmes EM (1903) Seaweeds of Abd-El-Kuri. In: Forbes HO (ed) The natural history of Socotra and Abd-El-Kuri. Young \& Sons, Liverpool, p 567-568

Kapraun DF (1980) Floristic affinities of North Carolina inshore benthic marine algae. Phycologia 19:245-252

Kemp JM (1997) Extensive coral reef communities of the Socotra Archipelago, Gulf of Aden. Coral Reefs 16:214

Kemp JM (1998a) The occurrence of Nizamuddinia zanardinii (Schiffner) P. C. Silva (Phaeophyta: Fucales) at the Socotra Archipelago. Bot Mar 41:345-348

Kemp JM (1998b) Zoogeography of the coral reef fishes of the Socotra Archipelago. J Biogeogr 25:919-933

Lapointe BE, Littler MM, Littler DS (1992) Nutrient availability to marine macroalgae in siliciclastic versus carbonate-rich coastal waters. Estuaries 15:75-82

Millar AJK, Kraft GT (1984) The red algal genus Acrosymphyton (Dumontiaceae, Cryptonemiales) in Australia. Phycologia 23:135-145

Ormond RFG, Banaimoon SA (1994) Ecology of intertidal macroalgal assemblages on the Hadramout coast of southern Yemen, an area of seasonal upwelling. Mar Ecol Prog Ser 105:105-120

Paulay G (1999) Corals. In: Planes S, Galzin R (eds) Preliminary Report Scientific Mission Oman 99, Sultanate of Oman, November-December 1999. Ardoukoba, Paris, p 25-27, 70-75

Paulay G, Meyer C (2001) Corals and marine invertebrates of the Sultanate of Oman-a progress report. In: 'Oman 99' Final Scientific Report. Ardoukoba, Paris, p 28-32

Randall JE, Hoover JP (1995) Scarus zhufar, a new species of parrotfish from southern Oman, with comments on endemism of the area. Copeia 1995:683-688

Reinicke GB, Al-Moghrabi S, DeVantier LM (2000) Soft corals of the Socotra Archipelago. In: Apel M, Hariri KI (eds) Conservation and sustainable use of biodiversity of Socotra Archipelago: marine habitat, biodiversity and fisheries surveys and management. Progress report of phase III. Senckenberg Research Institute, Frankfurt/M, p 81-96

Editorial responsibility: Otto Kinne (Editor), Oldendorf/Luhe, Germany
Schaminée JHJ, Stortelder AHF, Westhoff V (1995) De vegetatie van Nederland. Deel 1, inleiding tot de plantensociologie: grondslagen, methoden, toepassingen. Opulus Press, Uppsala-Leiden

Schils T, Coppejans E (2002) Gelatinous red algae of the Arabian Sea, including Platoma heteromorphum sp. nov. (Gigartinales, Rhodophyta). Phycologia 41:254-267

Schils T, Huisman JM (2003) Chamaebotrys erectus sp. nov. (Rhodymeniales, Rhodophyta) from the Socotra Archipelago, Yemen. Bot Mar 46:2-8

Schils T, De Clerck O, Leliaert F, Bolton JJ, Coppejans E (2001) The change in macroalgal assemblages through the Saldanha Bay/Langebaan Lagoon ecosystem (South Africa). Bot Mar 44:295-305

Schils T, De Clerck O, Coppejans E (2002) The red algal genus Reticulocaulis from the Arabian Sea, including $R$. obpyriformis Schils, sp. nov., with comments on the family Naccariaceae. Phycologia 42:44-55

Sheppard CRC, Salm RV (1988) Reef and coral communities of Oman, with the description of a new coral species (Order Scleractinia, genus Acanthastrea). J Nat Hist 22:263-279

Silva PC, Basson PW, Moe RL (1996) Catalogue of the benthic marine algae of the Indian Ocean. Univ Calif Publ Bot 79:1-1259

ter Braak CJF (1988) CANOCO_a FORTRAN program for canonical community ordination by (partial) (detrended) (canonical) correspondence analysis, principal component analysis and redundancy analysis (version 2.1). Manual, TNO, Wageningen

ter Braak CJF, Šmilauer P (1998) CANOCO reference manual and user's guide to Canoco for Windows: software for canonical community ordination (version 4). Microcomputer Power, Ithaca, NY

van der Maarel E (1979) Transformation of cover-abundance values in phytosociology and its effects on community similarity. Vegetatio 39:97-114

Wilson S (2001) Seawater temperatures in south-eastern Masirah Island. In: 'Oman 99' Final Scientific Report. Ardoukoba, Paris, p 34-36, 41

Wynne MJ (1998) Champia gigantea and Lomentaria strumosa (Rhodymeniales): two new red algae from the Sultanate of Oman. Bot Mar 42:571-580

Wynne MJ (1999a) Pseudogrinnellia barratiae gen. et sp. nov., a new member of the red algal family Delesseriaceae from the Sultanate of Oman. Bot Mar 42:37-42

Wynne MJ (1999b) New records of benthic marine algae from the Sultanate of Oman. Contrib Univ Mich Herb 22:189-208

Wynne MJ (2000) Further connections between the benthic marine algal floras of the northern Arabian Sea and Japan. Phycol Res 48:211-220

Wynne MJ (2001) New records of benthic marine algae from the Sultanate of Oman, northern Arabian Sea. II. Nova Hedwigia 72:347-374

Wynne MJ, Banaimoon SA (1990) The occurrence of Jolyna laminarioides (Phaeophyta) in the Arabian Sea and the Indian Ocean and a new report of Melanothamnus somalensis (Rhodophyta). Bot Mar 33:213-218

Wynne MJ, Jupp BP (1998) The benthic marine algal flora of the Sultanate of Oman: new records. Bot Mar 41:7-14

Wynne MJ, Leliaert F (2001) Pedobesia simplex (Kützing) comb. nov. (Chlorophyta), a new name for $P$. lamourouxii and its first report from the Indian Ocean. Cryptogam Algol 22:3-14

Zajonz U, Khalaf M, Krupp F (2000) Coastal fish assemblages of the Socotra Archipelago. In: Apel M, Hariri KI (eds) Conservation and sustainable use of biodiversity of Socotra Archipelago: marine habitat, biodiversity and fisheries surveys and management. Progress report of phase III. Senckenberg Research Institute, Frankfurt/M, p 127-170

Zar JH (1996) Biostatistical Analysis, 3rd edn. Prentice-Hall, Upper Saddle River, NJ

Submitted: July 18, 2002; Accepted: November 6, 2002

Proofs received from author(s): March 13, 2003 